\title{
Toward characterizing the demographics of introductory physics courses
}

\author{
Raphael Mondesir \\ Department of Sociology, Seattle Pacific University, 3307 Third Avenue West, Seattle, WA, 98119 \\ Amy D. Robertson \\ Department of Physics, Seattle Pacific University, 3307 Third Avenue West, Seattle, WA, 98119
}

Recent work by Kanim and Cid [1] suggests that the data used in PER is not representative of students enrolled in physics courses at the national level. Using university-level demographics, Kanim and Cid showed that PER studies oversample from white, wealthy, mathematically-prepared populations of students. What we do not yet know is whether these university-level demographics are representative of introductory physics courses, which are a primary site of research in PER. In this paper we present data from six US institutions, comparing the composition of introductory physics classes to aggregate university demographics in terms of gender and race and/or ethnicity. Our aim is to make progress in characterizing the demographics of introductory physics courses, which is imperative to deepening our understanding of how social disparity is manifested in physics classrooms and the institutions that host them. We discuss limitations of our approach, including problematizing the use of statistics to make sense of who is enrolling in introductory physics. 


\section{INTRODUCTION}

In a recent meta-analysis of physics education research (PER) studies published between 1975 and 2015, Kanim and Cid [1] showed that PER oversamples from White, wealthy, mathematically-prepared populations of students. They name several problems this creates, from limiting the generalizability of our field's claims to constructing an implicit norm (White, wealthy, mathematically-prepared student) that reinforces deficit framings of the participation and performance of students from underrepresented groups. The authors call on the PER community to attend to and design for population variability, encouraging researchers to provide "more detailed descriptions of our research populations" and to choose research subjects in ways that are conscious of who is being included and excluded.

Kanim and Cid's work problematizes the representativeness of the sample of students that PER has used to produce insights about the teaching and learning of physics. To know whether a sample is representative, we have to know about both the sample - the slice of a population being studied (e.g., students in introductory physics courses at Institution $X$ ) - and the target population - the overall group of people we are trying to characterize or describe (e.g., introductory physics students) [2]. In many cases, we do not know the demographics of either. Indeed, Kanim and Cid found that most PER studies in their analysis did not include the demographics of their samples, ${ }^{1}$ and our community has not yet aggregated demographic data about introductory physics courses [3], which is the population that most PER studies draw from. In the absence of demographic information about the samples in their meta-analysis, Kanim and Cid used institution-level data, assuming a one-to-one mapping between university-wide data and introductory physics classes. They then constructed a picture of the demographics of PER by weighting the approximated samples. In the absence of data about the target population (introductory physics courses), Kanim and Cid used data about college-bound or SAT-taking students. This proxy allowed them to compare the approximated demographics of PER studies to the approximated demographics of the target population. In short, in seeking to answer the question of whether PER sampling has been representative of introductory physics students, Kanim and Cid had to approximate both the sample and the target population.

As Kanim and Cid point out, introductory physics courses' demographics may not be representative of university-level demographics. In our study, we are posing the question, "Are the racial and/or ethnic, gender, and wealth demographics of introductory physics courses representative of the racial and/or ethnic, gender, and wealth demographics of the institution?" Answering this question

\footnotetext{
1 This omission masks the whiteness, wealth, and mathematical preparedness of the samples PER has drawn from. This masking is part of the mechanism by which whiteness (and other markers of dominance)
}

will help us make progress toward even more specificity in our description of the sample of students that PER has been studying, including who has been included and left out. Here, we report preliminary findings regarding gender and racial and/or ethnic demographics from six US universities, and we explore some implications of our analysis.

\section{RESEARCH METHODS}

In this section, we describe the methods we used to pursue our research question. Our general approach was to directly compare classroom level (1) gender and (2) racial and/or ethnic demographics with university-level demographics for six US universities.

\section{A. Sampling}

Our research question was inspired by Kanim and Cid's work [1] and emerged in the context of a research project that seeks to characterize university student resources for understanding physics. Both for the purposes of (i) characterizing the demographics of our project data set and (ii) answering the research question we pose in this paper, we requested demographic data for the introductory physics courses at each participating institution as well as aggregate demographic data for the institution overall. We requested data from a total of nine institutions and used the information from six for this analysis. This choice was informed strictly by when the information became available to us; institutions who sent us information before the start of our analysis were included. Our sample covers every major geographic region in the US, with Institution A located in the Southwest, B in the Midwest, C in the Southeast, D and E in the Northwest, and $\mathrm{F}$ in the Northeast. Two of the institutions (A and $\mathrm{E}$ ) are predominantly White [4], private, liberal arts universities with undergraduate enrollment below 15,000. Two of them are public research universities, $\mathrm{C}$ with enrollment above 20,000 and $\mathrm{D}$ with enrollment slightly above 5,000. Of the remaining two institutions, one is a public, predominantly Black college [5] with an enrollment close to 2,000 (B), and the other a community college with enrollment nearing 9,000 where minority groups account for over $50 \%$ of the student body $(\mathrm{F})$. Across these six schools, we obtained information on a total of 59,753 students; among them 1785 were enrolled in physics courses in the Fall of 2019. Using this data, we directly compare the composition of physics classrooms to that of the institution overall.

Our sample thus constitutes a convenience sample $[6,7]$. The likelihood of achieving representativeness is much more favorable with a random sampling process. However, this sampling is reasonable in the absence of such a sampling frame, and given the exploratory nature of this study.

become the "invisible norm" against which "others" are constructed, and contributes to the maintenance of hierarchies of dominance $[8,9]$. 


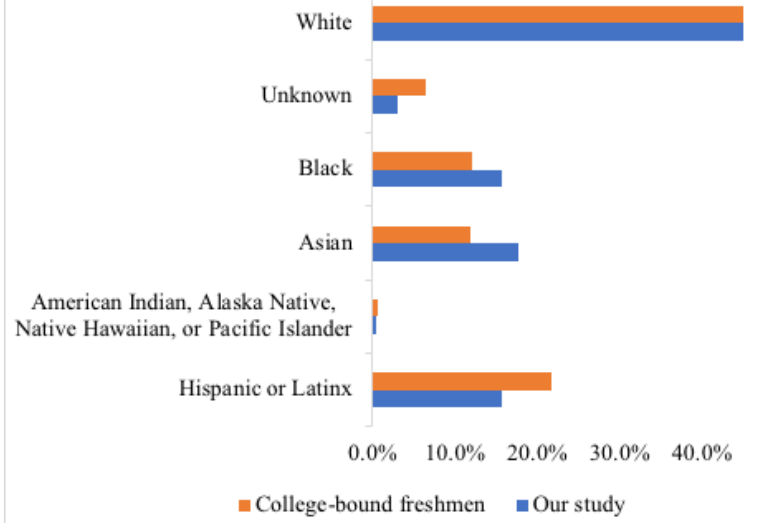

FIG. 1. Racial and/or ethnic demographics of institutions in our sample (blue) vs all college-bound freshmen (orange). As explained by Kat Lazo [10], neither Hispanic nor Latinx are racial groups, and these two identities are not the same. "Hispanic" is a descriptor for people of Spanish-speaking origins, and "Latinx" is a descriptor for people with origins in Latin America. The former focuses on language, the latter on geographic location. We combined American Indian, Alaska Native, Native Hawaiian, and Pacific Islander as a group to mirror the reporting of national trends in Kanim and Cid [1].

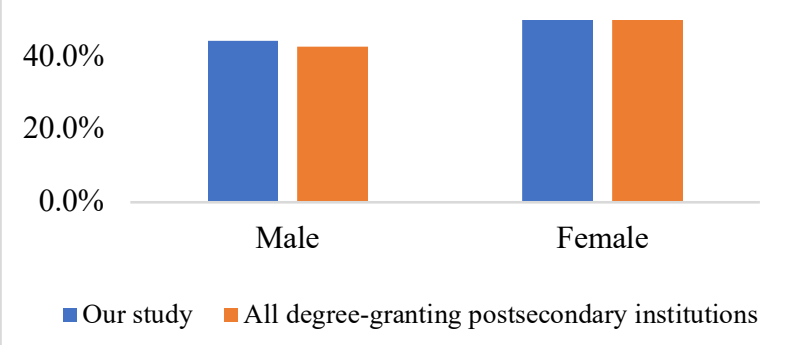

FIG. 2. Gender demographics of institutions in our sample (blue) vs all degree-granting postsecondary institutions (orange). Our data sources treat gender as a binary. We object to this ascription, even as we acknowledge that our work is reifying it.

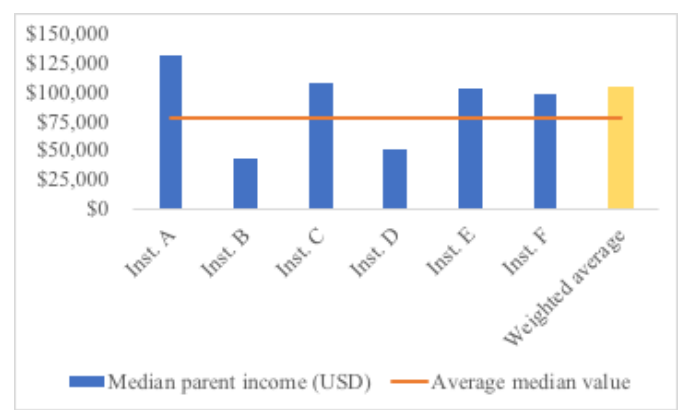

FIG. 3. Wealth demographics of institutions in our sample (blue bars) versus the average median value (orange line).

Because we used a non-probability sampling method, it is important to compare the gender, wealth, and racial and/ or ethnic demographics of the institutions in our study to those for all US institutions - i.e., to ask whether the institutions in our study are representative of US institutions on the whole along these measures. Figures 1 through 3 show the racial and/or ethnic, gender, and wealth demographics of the institutions in our study (sample), as compared to data available about institutions across the US (target population). In Figures 1 and 2, blue bars were constructed using demographic data provided by offices of institutional research (OIRs), weighted by sample size. Orange bars were constructed using data from Kanim and Cid [1] (Fig. 1) and the National Center for Educational Statistics [11] (Fig. 2). All of the data in Fig. 3 was obtained from the Equality of Opportunity Project [12], excepting data for Institution D, which was obtained from their OIR. Together, these figures show that our preliminary study is oversampling from institutions that serve Asian (including Asian American) students and students whose parental income is higher than the average median value. Our study is undersampling from institutions that serve Hispanic or Latinx students.

\section{B. Analysis}

In order to make progress in answering our research question - are the racial and/or ethnic and gender demographics of introductory physics courses representative of these demographics at the institutional level - we compared university-level demographics with those of introductory physics courses. Since each demographic dimension or grouping (gender, race and/or ethnicity) is a nominal variable with more than one category, we used Pearson's chi-square test of goodness-of-fit. This statistical procedure is ideal for situations where one needs to determine whether the distribution of cases in a nominal variable (e.g., the proportion of White students in an introductory physics course at Institution X) follow a known distribution (e.g., the overall proportion of White students at the institution) $[13,14]$. Where the expected classroom-level frequencies were very small (less than 5), we used Williams' continuity correction for more accurate estimates [13].

The analysis and writing of this paper were informed by the lived and learned experiences of both authors. Mondesir is a straight, cisgender, Black male of Caribbean ancestry with a Ph.D. in Sociology. Robertson is a straight, cisgender, White, disabled woman with a Ph.D. in Physics. Having experienced contexts of respective marginalization, we bring to this work a resonance and a shared investment in collective liberation, but we also recognize that our analytical tools of choice (statistics, formal logic, etc.) reflect a privileged access to systems of knowledge that, historically, have been used as apparatuses of domination against the very groups we are researching $[15,16]$.

\section{RESULTS}

We know both that the physics major is overwhelmingly White and that the fraction of bachelor's degrees earned by underrepresented racial and/or ethnic minorities is significantly less than expected given the fraction of the graduate-age population that is made up of people in these groups $[17,18]$. In contrast to what these statistics might lead 
TABLE I. Comparing distributions of racial and/or ethnic groups at the institutional and classroom levels

\begin{tabular}{|c|c|c|c|c|c|c|c|c|c|c|c|c|c|c|c|}
\hline & \multicolumn{2}{|c|}{$\begin{array}{c}\text { Hispanic or } \\
\text { Latinx }\end{array}$} & \multicolumn{2}{|c|}{ Black } & \multicolumn{2}{|c|}{$\begin{array}{c}\text { Native } \\
\text { American }\end{array}$} & \multicolumn{2}{|c|}{ Asian } & \multicolumn{2}{|c|}{$\begin{array}{l}\text { Pacific } \\
\text { Islander }\end{array}$} & \multicolumn{2}{|c|}{ White } & \multicolumn{2}{|c|}{$\begin{array}{c}\text { Race } \\
\text { unknown } \\
\text { or other }\end{array}$} & \multirow[t]{2}{*}{$\begin{array}{c}\text { Chi-square } \\
\text { tests }^{\mathrm{a}}\end{array}$} \\
\hline & $\%$ & $n$ & $\%$ & $n$ & $\%$ & $n$ & $\%$ & $n$ & $\%$ & $n$ & $\%$ & $n$ & $\%$ & $n$ & \\
\hline $\begin{array}{l}\text { Inst. A } \\
\text { Overall } \\
\text { Physics }\end{array}$ & $\begin{array}{l}16.3 \\
12.4\end{array}$ & $\begin{array}{c}2193 \\
11\end{array}$ & $\begin{array}{l}5.8 \\
5.6\end{array}$ & $\begin{array}{c}774 \\
5\end{array}$ & $\begin{array}{l}0.4 \\
2.2\end{array}$ & $\begin{array}{c}52 \\
2\end{array}$ & $\begin{array}{c}7.5 \\
18.0\end{array}$ & $\begin{array}{c}1002 \\
16\end{array}$ & $\begin{array}{l}0.1 \\
0.1\end{array}$ & $\begin{array}{c}15 \\
1\end{array}$ & $\begin{array}{l}64.5 \\
60.7\end{array}$ & $\begin{array}{c}8650 \\
54\end{array}$ & $\begin{array}{l}5.4 \\
0.0\end{array}$ & $\begin{array}{c}731 \\
0\end{array}$ & $\begin{array}{c}\chi^{2}(6)=34.65 \\
p<0.01 \\
n=89\end{array}$ \\
\hline $\begin{array}{l}\text { Inst. B } \\
\text { Overall } \\
\text { Physics }\end{array}$ & $\begin{array}{l}10.3 \\
28.6\end{array}$ & $\begin{array}{c}218 \\
2\end{array}$ & $\begin{array}{l}72.9 \\
28.6\end{array}$ & $\begin{array}{c}1536 \\
2\end{array}$ & $\begin{array}{l}0.0 \\
0.0\end{array}$ & $\begin{array}{l}0 \\
0\end{array}$ & \multicolumn{2}{|c|}{$\begin{array}{l}\%^{\mathrm{c}} \\
0.9\end{array}$} & \multicolumn{2}{|c|}{$\begin{array}{c}n^{\mathrm{c}} \\
19 \\
0\end{array}$} & $\begin{array}{l}3.8 \\
0.0\end{array}$ & $\begin{array}{c}81 \\
0\end{array}$ & $\begin{array}{l}12.0 \\
42.9\end{array}$ & $\begin{array}{c}254 \\
3\end{array}$ & $\begin{array}{c}\chi^{2}(4)=8.73 \\
p=0.07 \\
n=7\end{array}$ \\
\hline $\begin{array}{l}\text { Inst. C } \\
\text { Overall } \\
\text { Physics }^{\text {b }}\end{array}$ & $\begin{array}{l}17.4 \\
11.3\end{array}$ & $\begin{array}{c}4033 \\
125\end{array}$ & $\begin{array}{l}12.7 \\
13.0\end{array}$ & $\begin{array}{c}2947 \\
143\end{array}$ & $\begin{array}{l}0.1 \\
0.1\end{array}$ & $\begin{array}{c}29 \\
1\end{array}$ & $\begin{array}{l}23.4 \\
27.9\end{array}$ & $\begin{array}{c}5437 \\
308\end{array}$ & $\begin{array}{l}0.2 \\
0.0\end{array}$ & $\begin{array}{c}52 \\
0\end{array}$ & $\begin{array}{l}42.9 \\
44.4\end{array}$ & $\begin{array}{c}9957 \\
490\end{array}$ & $\begin{array}{l}3.3 \\
3.3\end{array}$ & $\begin{array}{c}776 \\
36\end{array}$ & $\begin{array}{c}\chi^{2}(6)=35.96 \\
p<0.01 \\
n=1103\end{array}$ \\
\hline $\begin{array}{l}\text { Inst. D } \\
\text { Overall } \\
\text { Physics }\end{array}$ & $\begin{array}{c}11.7 \\
6.0\end{array}$ & $\begin{array}{c}590 \\
14\end{array}$ & $\begin{array}{l}8.5 \\
6.0\end{array}$ & $\begin{array}{c}428 \\
14\end{array}$ & $\begin{array}{l}0.5 \\
0.0\end{array}$ & $\begin{array}{c}26 \\
0\end{array}$ & $\begin{array}{l}33.3 \\
42.9\end{array}$ & $\begin{array}{c}1683 \\
100\end{array}$ & $\begin{array}{l}0.6 \\
0.0\end{array}$ & $\begin{array}{c}32 \\
0\end{array}$ & $\begin{array}{l}43.5 \\
43.3\end{array}$ & $\begin{array}{c}2197 \\
101\end{array}$ & $\begin{array}{l}1.9 \\
1.7\end{array}$ & $\begin{array}{c}98 \\
4\end{array}$ & $\begin{array}{c}\chi^{2}(6)=17.18 \\
p<0.01 \\
n=233\end{array}$ \\
\hline $\begin{array}{l}\text { Inst. E } \\
\text { Overall } \\
\text { Physics }\end{array}$ & $\begin{array}{l}16.5 \\
18.0\end{array}$ & $\begin{array}{c}378 \\
21\end{array}$ & $\begin{array}{l}6.1 \\
8.0\end{array}$ & $\begin{array}{c}141 \\
9\end{array}$ & $\begin{array}{l}0.4 \\
0.0\end{array}$ & $\begin{array}{l}9 \\
0\end{array}$ & $\begin{array}{l}15.7 \\
19.0\end{array}$ & $\begin{array}{c}360 \\
23\end{array}$ & $\begin{array}{l}1.0 \\
1.0\end{array}$ & $\begin{array}{c}22 \\
1\end{array}$ & $\begin{array}{l}57.1 \\
53.0\end{array}$ & $\begin{array}{c}1311 \\
63\end{array}$ & $\begin{array}{l}3.2 \\
3.0\end{array}$ & $\begin{array}{c}73 \\
3\end{array}$ & $\begin{array}{c}\chi^{2}(6)=2.45 \\
p=0.87 \\
n=120\end{array}$ \\
\hline $\begin{array}{l}\text { Inst. F } \\
\text { Overall } \\
\text { Physics }\end{array}$ & $\begin{array}{c}12.8 \\
3.0\end{array}$ & $\begin{array}{c}1161 \\
1\end{array}$ & $\begin{array}{l}30.8 \\
18.0\end{array}$ & $\begin{array}{c}2798 \\
7\end{array}$ & $\begin{array}{l}0.2 \\
0.0\end{array}$ & $\begin{array}{c}21 \\
0\end{array}$ & $\begin{array}{l}13.5 \\
18.0\end{array}$ & $\begin{array}{c}1230 \\
7\end{array}$ & $\begin{array}{l}0.1 \\
0.0\end{array}$ & $\begin{array}{c}13 \\
0\end{array}$ & $\begin{array}{l}31.5 \\
47.0\end{array}$ & $\begin{array}{c}2861 \\
18\end{array}$ & $\begin{array}{l}11.0 \\
13.0\end{array}$ & $\begin{array}{c}997 \\
5\end{array}$ & $\begin{array}{c}\chi^{2}(6)=8.66 \\
p=0.19 \\
n=38\end{array}$ \\
\hline
\end{tabular}

'Williams' continuity correction applied to all tests.

bIncludes multiple introductory physics courses at this institution.

'Institution B reported Asian \& Pacific Islander as a single racial and/or ethnic group.

TABLE II. Comparing distributions of gender groups at the institutional and classroom levels. ${ }^{\text {a }}$

\begin{tabular}{|c|c|c|c|c|c|}
\hline & \multicolumn{2}{|c|}{ Male } & \multicolumn{2}{|c|}{ Female } & \multirow[t]{2}{*}{ Chi-square tests } \\
\hline & $\%$ & $n$ & $\%$ & $n$ & \\
\hline $\begin{array}{l}\text { Inst. A } \\
\text { Overall } \\
\text { Physics }\end{array}$ & $\begin{array}{l}40.5 \\
68.5\end{array}$ & $\begin{array}{c}5711 \\
63\end{array}$ & $\begin{array}{l}59.5 \\
31.5\end{array}$ & $\begin{array}{c}8397 \\
29\end{array}$ & $\begin{array}{c}\chi^{2}(1)=30.56 \\
p<0.001 \\
n=92\end{array}$ \\
\hline $\begin{array}{l}\text { Inst. B } \\
\text { Overall } \\
\text { Physics }\end{array}$ & $\begin{array}{l}30.2 \\
43.0\end{array}$ & $\begin{array}{c}636 \\
3\end{array}$ & $\begin{array}{l}69.8 \\
57.0\end{array}$ & $\begin{array}{c}1472 \\
4\end{array}$ & $\begin{array}{c}\chi^{2}(1)=0.65^{\mathrm{b}} \\
p=0.42 \\
n=7\end{array}$ \\
\hline $\begin{array}{l}\text { Inst. C } \\
\text { Overall } \\
\text { Physics }\end{array}$ & $\begin{array}{l}50.6 \\
58.3\end{array}$ & $\begin{array}{c}13168 \\
721\end{array}$ & $\begin{array}{l}49.3 \\
41.7\end{array}$ & $\begin{array}{c}12845 \\
515\end{array}$ & $\begin{array}{c}\chi^{2}(1)=26.53 \\
p<0.001 \\
n=1236\end{array}$ \\
\hline $\begin{array}{l}\text { Inst. D } \\
\text { Overall } \\
\text { Physics }\end{array}$ & $\begin{array}{l}49.0 \\
80.2\end{array}$ & $\begin{array}{c}2815 \\
211\end{array}$ & $\begin{array}{l}51.0 \\
19.8\end{array}$ & $\begin{array}{c}2919 \\
52\end{array}$ & $\begin{array}{c}\chi^{2}(1)=102.3 \\
p<0.001 \\
n=263\end{array}$ \\
\hline $\begin{array}{l}\text { Inst. E } \\
\text { Overall } \\
\text { Physics }\end{array}$ & $\begin{array}{l}34.0 \\
50.3\end{array}$ & $\begin{array}{c}909 \\
75\end{array}$ & $\begin{array}{l}66.0 \\
49.7\end{array}$ & $\begin{array}{c}1800 \\
74\end{array}$ & $\begin{array}{c}\chi^{2}(1)=18.81 \\
p<0.001 \\
n=149\end{array}$ \\
\hline $\begin{array}{l}\text { Inst. F } \\
\text { Overall } \\
\text { Physics }\end{array}$ & $\begin{array}{l}41.3 \\
62.9\end{array}$ & $\begin{array}{c}3410 \\
22\end{array}$ & $\begin{array}{l}58.7 \\
37.1\end{array}$ & $\begin{array}{c}4853 \\
13\end{array}$ & $\begin{array}{c}\chi^{2}(1)=6.54 \\
p<0.05 \\
n=35\end{array}$ \\
\hline
\end{tabular}

${ }^{\mathrm{a}}$ Operationalizing gender as a binary, as this data does, is inaccurate and problematic [19].

'Using Williams' continuity correction

us to expect, introductory physics courses at the institutions in our study are not disproportionately White, as compared to university-level demographics (Table I). In fact, there is an overrepresentation of Asian students and an underrepresentation of Black and Latinx students in introductory physics courses. $\left(\chi^{2}\right.$ is a measure of difference, such that the larger the difference between the universityand classroom-level demographics, the larger the $\chi^{2}$ value in the right-most column.) This over- and underrepresentation is affirmed by the chi-square contributions for each racial and/or ethnic group. In particular, the Hispanic/Latinx and Asian groups made the largest contributions to the differences between the institution- and classroom-level data. For instance, at Institution D, these figures were 6.47 for Asian students and 6.41 for the Hispanic/Latinx category, out of a total $\chi^{2}$ of 17.18 .

As shown in Table II, the chi-square tests on gender categories show a significant difference between the percentages of male and female students in introductory physics classes and their proportions in the overall population at the institutions in our study. Only the data from Institution B yielded non-significant results. These findings suggest male students are overrepresented in the introductory physics courses at the institutions in our study, and female students are underrepresented. For instance, despite female students outnumbering male students by a ratio of 2 to 1 at Institution E overall, there are just as many females as males in the introductory physics classes.

\section{DISCUSSION}

Our results suggest that in the introductory physics courses at the six institutions in our study, female students 
are under-represented and male students are overrepresented compared to institution-level demographics. Further, Asian students are over-represented, and Black and Hispanic or Latinx students are under-represented in the courses in our sample. White students are neither over- nor under-represented in introductory physics courses, when compared to university-level demographics; however, they constitute the largest racial and/or ethnic group in five of the six introductory physics courses in our sample.

These findings are not generalizable, since this is an exploratory attempt that relies on a convenience sample. To more accurately assess the representativeness of the samples used in PER, we would need a more systematic and random sampling strategy [2,6,7]. However, if our preliminary findings do point to a larger trend, a question we are exploring, they pose a number of questions and implications.

First, Kanim and Cid's meta-analysis [1] used universitylevel demographic data to show that PER studies oversample from White, wealthy, mathematically-prepared populations. In our preliminary study, the demographic composition of physics courses is even more skewed than the university's, particularly with respect to Black, Latinx or Hispanic, and female students. If we find that this is the case for more institutions, Kanim and Cid's assertion that PER has relied on a "narrow sampling" of racial and/or ethnic groups is even more dramatic than the university-level demographics in their study would predict. As Kanim and Cid point out, such narrow sampling, when not coupled with transparent reporting of sample demographics, risks reinforcing harmful stereotypes about gender and racial and/or ethnic groups and their presence in disciplines like physics that traditionally select a majority of White students. An outcome of such studies is a set of conclusions that apply to a specific group but are erroneously used to make generalizable predictions about physics teaching and learning.

Second, that we are seeing disproportionately fewer Black, Latinx, and female students in introductory physics courses, as compared to university-level demographics, is an outcome that signals gendered and racialized oppression in introductory physics. Similar outcomes are signaled by statistics about residential segregation, incarceration rates, income disparities, etc., in the US [20]. These findings, if generalizable, raise questions about mechanisms of oppression in physics teaching and learning. For example, might there be self-reinforcing mechanisms that contribute to the maintenance of specific, persistent dynamics of oppression? Is student enrollment in introductory physics courses a manifestation of these mechanisms? We can envision that physics departments exert significant effort to recruit students, but that students also self-select into physics courses. Are undergraduate students likely to enroll in courses taught by faculty who do not look or sound like them? Are faculty recruiting students that fit a certain profile? And how does the racial and/or ethnic and gender composition of the introductory physics course shape future enrollment decisions for students? For example, when there is a single Black student in an introductory physics class, stereotype threat - a set of harmful expectations attached to a person's identity that creates internal ambiguity regarding how they should behave or how their peers perceive them [21] - may become one filter through which that student experiences the course. One of the authors (Mondesir) has had first-hand experiences of how this kind of racial anxiety can severely impede learning in the classroom. All of these are examples of possible relationships between oppression, representation, and experience.

In our analysis, the Native American and Pacific Islander racial and/or ethnic groups have received very little attention. These groups make up the smallest proportion of the student body both nationally and in our sample (see Figure 1); in our data set, this means that we cannot make statistical comparisons for these groups. Their lack of visibility in the data and in our subsequent analysis is reflective of the invisibility of indigenous groups at larger scales and is being actively addressed by Native-led organizations like IllumiNatives [22]. We have also given little attention to the over-representation of Asian students in the physics courses in our sample. This represents a limitation in our own understanding of the dynamics of antiAsian racism. What we do understand is that the harmful "model minority" stereotype has been deployed in service of maintaining the myth of meritocracy [23], and we do not want our results to be misinterpreted in this way.

All of these questions point us to a need for further exploration and self-education. Statistical analyses can play a role in this exploration, in further specifying possible sites of racialized and gendered oppression within undergraduate physics education. (Most existing statistics focus on the demographics of students awarded degrees [24,25].) However, statistics also reinforce and reify oppression. As a discipline, Statistics emerged from the eugenics movement, for the purposes of justifying a racial hierarchy [16], and the gender binary persists as a standard codification of students, which marginalizes non-binary students [19]. Further, statistical categorization masks the intersectional nature of oppression, constructing marginalization as unidimensional: race or gender or class, etc. [26]. In Audre Lorde's [15] words, these categories and the techniques deployed to analyze them remain the master's tools. Thus, this work also points to a need for accounts of lived experience (e.g., [27-30]), which speak to oppression in a more direct and embodied way [29], including work that documents the experiences of students from various gendered and racialized groups in physics.

\section{ACKNOWLEDGMENTS}

The authors gratefully acknowledge the support and feedback of Lauren C. Bauman, Lisa M. Goodhew, Paula R. L. Heron, Steve Kanim, McKensie Mack, and Rachel E. Scherr. This work was supported in part by NSF Grants 1914603, 1914572, and 1760761. 
[1] https://arxiv.org/abs/1710.02598. Retrieved 10/2/2018.

[2] A. Field, Discovering Statistics Using SPSS (SAGE Publications, Inc., Thousand Oaks, CA, 2009), $3^{\text {rd }}$ Ed.

[3] P. Mulvey (private communication).

[4]

http://sk.sagepub.com/reference/africanamericaneducation/n1 93.xml. Retrieved 5/13/2020.

[5] https://uscode.house.gov/view.xhtml?req=granuleid:USCprelim-title20-section $1059 \mathrm{e} \&$ num $=0 \&$ edition=prelim. Retrieved 5/19/2020.

[6] I. Etikan, S. A. Musa, and R. S. Alkassim, Am. J. Theor. App. Stat. 5, 1 (2016).

[7] W. McCready, in The psychology research handbook: A guide for graduate students and research assistants, edited by $\mathrm{F}$. Leong and J. Austin (SAGE Publications, Thousand Oaks, CA, 2006), p. 147.

[8] A. W. Doane and E. Bonilla-Silva, White Out: The Continuing Significance of Racism (Routledge, New York, 2003).

[9] K. Crenshaw, N. Gotanda, G. Peller, and K. Thomas, Critical Race Theory: The Key Writings that Formed the Movement (The New Press, New York, 1995).

[10] https://www.vox.com/2016/8/28/12658908/latino-hispanicrace-ethnicity-explained. Retrieved 5/19/2020.

[11] https://nces.ed.gov/programs/digest/d19/tables/dt19 303.10.a sp. Retrieved 4/18/2020.

[12] https://opportunityinsights.org/. Retrieved 2/7/2020.

[13] J.H. McDonald, Handbook of Biological Statistics (Sparky House Publishing, Baltimore, MD, 2014), $3^{\text {rd }} \mathrm{Ed}$.

[14] D. J. Sheskin, Handbook of Parametric and Nonparametric Statistical Procedures (CRC Press, 2003), $3^{\text {rd }}$ Ed.

[15] A. Lorde, Sister Outsider (Ten Speed Press, New York, 2007).

[16] T. Zuberi and E. Bonilla-Silva, White Logic, White Methods: Racism and Methodology (Rowman \& Littlefield Publishers, Lanham, MD, 2008).

[17] https://www.aps.org/programs/education/statistics/urm.cfm. Retrieved 4/28/2020.

[18]

https://www.aps.org/programs/education/statistics/phdpopulat ion.cfm. Retrieved 4/28/2020.

[19] M. Mack, "How to Write About Gender" (webinar, 10/23/20).

[20] E. Bonilla-Silva, Racism Without Racists: Color-Blind Racism and the Persistence of Racial Inequality in America (Rowman \& Littlefield, Lanham, MD, 2018), $5^{\text {th }}$ Ed.

[21] C. Steele and J. Aronson, Personality Soc. Psych. 69, 797 (1995).

[22] https://illuminatives.org/. Retrieved 5/19/2020.

[23] R. S. Chou and J. R. Feagin, The Myth of the Model Minority: Asian Americans Facing Racism (Routledge, New York, 2016), $2^{\text {nd }} \mathrm{Ed}$.

[24]

https://www.aps.org/programs/minorities/resources/statistics.c fm. Retrieved 5/19/2020.

[25] https://www.aip.org/statistics/minorities. Retrieved $5 / 19 / 2020$

[26] K. Crenshaw, Stanford Law Rev. 43, 1241 (1990).
[27] S. Herrera, I. A. Mohamed, and A. R. Daane, Phys. Teach. 58, 294 (2020).

[28] K. Rosa and F. M. Mensah, Phys. Rev. PER 12, 020113 (2016).

[29] R. S. Barthelemy, M. McCormick, and C. Henderson, Phys. Rev. PER 12, 020119 (2016).

[30] P. H. Collins, Black Feminist Thought (Routledge, New York, 2000). 